
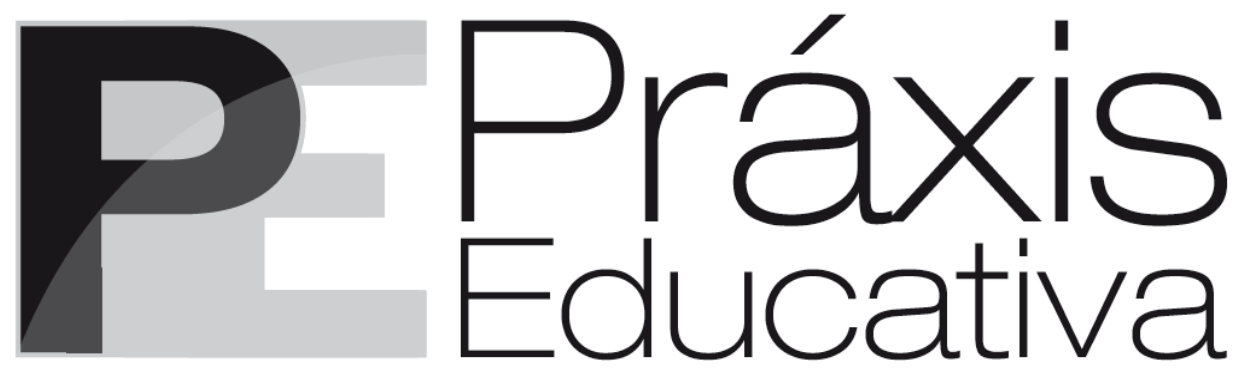

ISSN 1809-4031

eISSN 1809-4309

https://doi.org/10.5212/PraxEduc.v.16.16683.039

\title{
O legado de Paulo Freire em marcha na Educação e na Escola do Campo
}

\section{Paulo Freire's legacy on the march in Education and Countryside School}

\section{El legado de Paulo Freire en marcha en la Educación y en la Escuela Rural}

\author{
Iranete Maria da Silva Lima* \\ http:// orcid.org/0000-0003-4817-2488 \\ Salomão Antônio Mufarrej Hage ${ }^{* *}$ \\ iD http://orcid.org/0000-0001-7801-0696 \\ Dileno Dustan Lucas de Souza** \\ http://orcid.org/0000-0001-6053-8273
}

\begin{abstract}
Resumo: Este artigo é fruto de nossos estudos desenvolvidos no âmbito do Grupo de Estudos e Pesquisas em Educação do Campo na Amazônia (GEPERUAZ) sobre as contribuições do legado de Paulo Freire para a Educação e a Escola do Campo. O estudo parte da premissa de que suas raízes estão intrinsecamente ligadas à Educação Popular. Para a elaboração deste texto, contamos com um estudo bibliográfico e documental que fundamentou as evidências que apresentamos sobre as contribuições da teoria freireana para a compreensão dos desafios que se impõem à educação e à sociedade brasileira na atualidade. As relações existentes entre a Educação Popular e a Educação do Campo traduzem-se em iniciativas exitosas de formação/escolarização que estão em marcha em face do protagonismo do Movimento da Educação do Campo nos seus 20 anos de existência.

Palavras-chave: Teoria freireana. Educação Popular. Educação do Campo.
\end{abstract}

Abstract: This paper is the result of our studies developed within the Study and Research Group on Countryside Education in the Amazon (Grupo de Estudos e Pesquisas em Educação do Campo na Amazônia GEPERUAZ) about the contributions of Paulo Freire's legacy to Education and Countryside School. The study is based on the premise that its backgrounds are intrinsically linked to Popular Education. For the

\footnotetext{
* Professora da Universidade Federal de Pernambuco (UFPE). Doutora em Matemática e Informática pela Université Joseph Fourier - UJF. E-mail: <Iranete.lima@ufpe.br>.

** Professor da Universidade Federal do Pará (UFPA). Doutor em Educação pela Pontifícia Universidade Católica de São Paulo (PUC/SP). E-mail: <salomao_hage@yahoo.com.br>.

*** Professor da Universidade Federal de Juiz de Fora (UFJF). Doutor em Educação pela Universidade Federal do Rio Grande do Sul (UFRGS). E-mail: <dilenodustand@gmail.com>.
} 
elaboration of this text, we counted on a bibliographic and documentary study that supported the evidence presented, on the contributions of Freire's theory to the understanding of the challenges that are imposed on education and on the Brazilian society today. The existing relations between Popular Education and Countryside Education translate into successful training/schooling initiatives that are underway in the face of the protagonism of the Countryside Education Movement in its 20 years of existence.

Keywords: Freirean theory. Popular Education. Field Education.

Resumen: Este artículo es fruto de nuestras estudios desarrollados en el ámbito del Grupo de Estudos y Pesquisas en Educación del Campo en Amazônia (GEPERUAZ) sobre las contribuciones del legado de Paulo Freire a la Educación y la Escuela del Campo. Partimos de la premisa de que sus raíces están intrínsecamente vinculadas a la Educación Popular. Para la elaboración de este texto, contamos con un estudio bibliográfico y documental que fundamentó las evidencias que presentamos sobre las contribuciones de la teoría freireana para la comprensión de los desafíos que se imponen a la educación y a la sociedad brasileña en la actualidad. Las relaciones existentes entre la Educación Popular y la Educación del Campo se traducen en iniciativas exitosas de formación/escolarización que están en marcha ante el protagonismo del Movimiento de la Educación del Campo en sus veinte años de existencia.

Palabras clave: Teoría freireana. Educación Popular. Educación del Campo.

\section{Introdução}

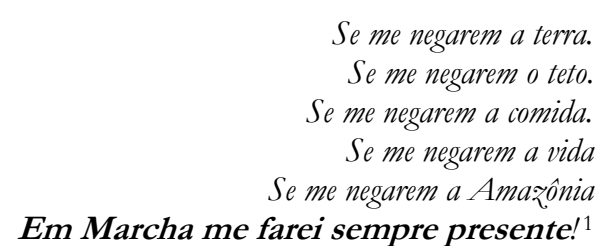

Em Marcha me farei sempre presente! ${ }^{1}$

Tempos complexos vivenciamos na atualidade com a intensificação de uma crise econômica histórica e estrutural acirrada ideologicamente com a emergência da pandemia da Covid-19. Esse quadro caótico acentuou as disputas pela hegemonia dos projetos sociais, em que a defesa da vida em todas as suas expressões se confronta com a afirmação do lucro como pauta central da economia.

Nesse cenário, a visão negacionista da pandemia, assentada na desvalorização da ciência e na revitalização das teorias criacionistas de base fundamentalista, tem se fortalecido por meio de uma aliança com o pensamento ultraneoliberal e de inspiração fascista. Essa aliança tem protagonizado uma perseguição ideológica ao pensamento crítico e, em particular, às ideias do educador Paulo Freire, fenômeno que, em uma perspectiva mais abrangente, também ocorre na América Latina e em muitos outros países.

O movimento bolsonarista, que emergiu após as eleições presidenciais de 2018 com a vitória de um governo resultante de uma ampla coalização de direita, tem como base de sustentação os neoconservadores evangélicos, os ruralistas e os empresários do agronegócio, associados à elite empresarial brasileira. Tal movimento se apresenta como portador da retomada dos valores morais cristãos da família e reproduz, em suas narrativas, um lema adaptado de slogan utilizado na Alemanha Nazista, o qual forja o conhecido "Brasil acima de tudo, Deus acima de todos".

Em busca de sobreviver, o movimento elegeu Paulo Freire como "inimigo prioritário" no campo ideológico e educacional. Assim, segundo o Conselho de Educação Popular da América Latina e do Caribe - CEAAL (2019, p. 1), tem-se implementado um conjunto de medidas como o

${ }^{1}$ Refrão da Mística de abertura do Evento da Cátedra Paulo Freire da Amazônia, apresentada pelos integrantes do Grupo de Estudos e Pesquisas em Educação do Campo na Amazônia (GEPERUAZ) no Auditório da Universidade Estadual do Pará (UEPA), em 25 de setembro de 2019 (grifo nosso). 
intuito de "expurgar Paulo Freire da educação", como consta no plano de governo Bolsonaro. Essas medidas envolvem pelo menos três táticas:

- Utilização de estratégia de marketing de produção importada dos Estados Unidos e disparo de fake news sobre os opositores - a Esquerda Brasileira e Paulo Freire -, com o intuito de construir, sob a liderança de ideólogos da extrema direita, uma rede empenhada em difamálos, apresentando-os como: "doutrinador/a", "degradação moral do país", "ameaça comunista à soberania nacional", "um perigo para a educação dos jovens", reivindicando inclusive a revogação da Lei No 12.612, de 13 de abril de 2012², a qual declarou Paulo Freire Patrono da Educação Brasileira (BRASIL, 2012).

- Desmonte e desqualificação dos princípios e dos fundamentos da educação pública, gratuita, laica, democrática e de qualidade, socialmente referenciada, projeto assumido abertamente por Paulo Freire e outros/as educadores/as e intelectuais críticos da área de educação, os quais apostam na pressão sobre o poder público para assegurar todos os princípios do Estado Democrático de Direito.

- Estabelecimento de mecanismos e de dispositivos legais que impõem formas coercitivas de controle sobre o trabalho docente para pôr fim à liberdade de cátedra e de ensino e impor um pensamento único, como: o projeto "Escola Sem Partido", "Militarização das Escolas", "Ensino Doméstico", "negação de políticas para a diversidade", todos a serviço da doutrinação e da colonização do pensamento.

$\mathrm{Na}$ contramão dessas medidas, este artigo une-se aos variados coletivos e movimentos de diferentes setores da sociedade civil brasileira, latino-americana e mundial, contra os ataques desse projeto neoconservador e neofascista, e soma-se à grande mobilização continental que vem sendo construída em defesa do legado e da memória de Paulo Freire, rumo às comemorações do centenário de seu nascimento em 19 de setembro de 2021. Para isso, apresentamos, neste artigo, uma síntese das nossas reflexões e discussões no âmbito do Grupo de Estudos e Pesquisas em Educação do Campo na Amazônia (GEPERUAZ), o qual tem sede na Universidade Federal do Pará (UFPA) e congrega pesquisadores de outras Universidades brasileiras com o intuito de enriquecer o debate e o acúmulo sobre a Educação do Campo.

Nossa reflexão constrói-se a partir de um estudo bibliográfico e documental realizado com a finalidade de melhor compreender as relações entre a teoria freireana e a Educação e a Escola do Campo, bem como as contribuições que a teoria freireana traz para o enfrentamento dos desafios que se impõem à educação e à sociedade brasileira na atualidade. Assim, para além deste texto introdutório, apresentamos nossa reflexão sobre a atualidade de Paulo Freire no cenário educacional brasileiro. Em seguida, trazemos as referências da relação existente entre a Educação Popular e a Educação do Campo, as quais se traduzem em iniciativas exitosas de formação/escolarização que estão em marcha em face ao protagonismo do Movimento da Educação do Campo nos seus 20 anos de existência.

\section{A atualidade de Paulo Freire no cenário educacional brasileiro}

O cenário adverso que vivenciamos no nosso continente, especialmente no Brasil, é marcado pelo aprofundamento das desigualdades sociais e dos processos históricos de opressão e

${ }^{2}$ Cabe acrescentar que, em 5 de setembro de 2019, a Comissão de Direitos Humanos e Legislação Participativa (CDH) do Senado Federal rejeitou a sugestão popular (SUG 27/2019) que pretendia revogar a Lei No 12.612/2012 (BRASIL, 2019). 
resulta da forte ofensiva do capital contra o trabalho. Com a implementação de contrarreformas neoliberais, acentua-se a retirada de direitos trabalhistas e sociais e promove-se o rebaixamento do nível de vida das trabalhadoras e dos trabalhadores, além do aumento da exploração e da transformação dos serviços públicos em negócios e mercadorias.

Nesse sentido, a defesa do legado freireano, em meio às celebrações do centenário de Freire, tem sido entendida como um momento importante de resistência aos ataques constantes à educação pública e ao processo de mercantilização da educação e da vida. Mais do que um encontro para manter vivo o legado de Paulo Freire, as comemorações do centenário constituem-se em uma potente estratégia de afirmação da defesa da educação pública como um direito social, inspirada nos seus ideais e em sua teoria. Elas fortalecem o entendimento de que os processos educativos, sejam eles escolares ou sociais, forjados nas lutas, nas marchas, nas múltiplas relações sociais existentes, podem assumir-se como uma grande possibilidade de liberação cultural, social e política, com participação da comunidade educativa e, particularmente, de setores historicamente excluídos e oprimidos.

Quando ousamos dizer que Paulo Freire apresentou referências de um outro paradigma de educação, é exatamente nisto que nos fundamentamos: no reconhecimento da importância dos processos educativos na formação humana de todos os sujeitos, mas especialmente daqueles que historicamente têm sido submetidos a processos brutais de marginalização, de exclusão e de opressão, "os esfarrapados do mundo", os pobres, os indigentes, os miseráveis, os sem-terra, os sem teto, os sem trabalho, considerados pelos defensores do paradigma hegemônico como inhumanos.

Em Educação como prática de liberdade (FREIRE, 1967), Freire advertiu-nos sobre o poder libertador das palavras, as quais podem deixar de ser o veículo das ideologias alienantes e se tornarem instrumento de uma transformação global, dos homens, das mulheres e de toda a sociedade. Em Pedagogia do oprimido, Freire (1987) apresenta sua defesa de uma educação libertadora, dialógica e transformadora, protagonizada pelos próprios oprimidos, explorados, subalternos, expropriados, escravizados, exilados, refugiados, privados de liberdade..., contra todas as formas de opressão existentes na sociedade. Arroyo (2019) corrobora essa defesa, ao afirmar que, para Freire, a tarefa da Educação, por conseguinte também da escola, dos educadores e das educadoras é reconhecer os milhões de educandos e educandas - que, desde a infância, enfrentam os processos brutais de marginalização, de exclusão e de opressão - como sujeitos de direito que lutam pela libertação-humanização-emancipação, pelo trabalho livre, pela desalienação e pela afirmação como pessoas e "seres para si".

Ciente de que nenhum projeto social ou paradigma educacional se concretiza com a utilização apenas de aparatos coercitivos e de imposição da violência e do arbítrio, Freire contrapõe o paradigma hegemônico, assentado em uma visão conservadora, reacionária e fundamentalista de mundo, que reforça as opressões impostas historicamente aos seguimentos, às classes e aos coletivos subalternos. Para tanto, como afirma Freire:

A pedagogia tem de ser forjada com ele (o oprimido) e não para ele, enquanto homens ou povos, na luta incessante de recuperação de sua humanidade. Pedagogia que faça da opressão e de suas causas objeto da reflexão dos oprimidos, de que resultará o seu engajamento necessário na luta por sua libertação, em que esta pedagogia se fará e refará. (FREIRE, 1987, p. 32).

Com essas reflexões, afirmamos as razões que justificam o fato de Paulo Reglus Neves Freire (1921-1997) ter sido declarado Patrono da Educação Brasileira e de estar ocorrendo uma ampla movimentação nacional-internacional para celebrar o centenário do nascimento desse nordestino, pernambucano do pé rachado, formado em Direito e Filosofia, educador militante e 
alfabetizador de Jovens e de Adultos, secretário municipal de Educação de São Paulo, a cidade mais populosa do Brasil e da América Latina.

Não bastasse ter obtido 48 títulos entre Doutorados honoris causa e outras honrarias de Universidades e organizações brasileiras e do exterior; ser Cidadão Honorário de importantes cidades brasileiras (Rio de Janeiro, Campinas, Belo Horizonte, Porto Alegre e outras); ter seu nome como referência na criação de Cátedras em várias instituições educativas brasileiras e internacionais; ter, entre suas publicações em vida, publicações póstumas, cartas, entrevistas, ensaios e artigos, um acervo de quase 40 livros publicados. Paulo Freire é considerado um dos pensadores mais notáveis na história da pedagogia mundial, com forte influência no movimento da educação crítica.

Em suas obras, Freire dedicou especial atenção aos educadores e às educadoras e tornouse referência fundante para legitimar os processos dialógicos, interativos e respeitosos com os estudantes e desenvolverem práticas pedagógicas com ética, autonomia e criticidade, de modo a valorizar as diversas culturas, as identidades, os saberes tradicionais e populares e as territorialidades. Ele dedicou também grande parte de sua vida à alfabetização e à educação da população pobre, excluída, oprimida, marginalizada, subalternizada. Com eles e elas, em comunhão, vivenciou experiências de educação dialógica, humanizadora e libertadora que valoriza as diferenças de gênero, sexo, raça, etnia, território, geração, saberes e sujeitos... Enfim, as múltiplas diversidades que estão sendo silenciadas, negadas e deslegitimadas na atualidade pelo atual Governo Federal.

Quanto mais analisamos as relações entre educadoras e educadores, educandas e educandos com a escola, mais nos convencemos da relevância dos ensinamentos de Paulo Freire para a vida em sociedade. Afirmamos com Freire (1987) que a educação não se reduz a uma prática em que aqueles que "sabem mais" se impõem sobre aqueles que "sabem menos". A pretensa hierarquia de saberes não passa de fetiche de uma sociedade que, como afirma Frigotto (1984), produz e alimenta a exclusão e a marginalização como referências pedagógicas de uma sociedade que preza pela teoria do capital humano.

Assim, pensar em educação no Brasil remete, seguramente, a Paulo Freire, educador tão atual quanto emblemático, que desnuda as falas da escuridão dos porões que se apresentam com a intensidade de um pensamento único e incapaz de admitir a diversidade dos povos que constituem a sociedade brasileira. Os arautos do pensamento único anunciam o ódio ao que é diferente e diverso. Por isso, palavras como "quilombola" e "indígena", as quais expressam a riqueza das etnias e da luta dos povos brasileiros, lhes constrangem e indignam. Todavia, que povos são esses?

Paulo Freire, ao apresentar a Pedagogia do oprimido, saúda-nos com uma sensibilidade jamais encontrada na reflexão educacional e pedagógica. Ele inicia pela exaltação do poder da conscientização como fator de transformação de uma sociedade, por meio da participação e da intervenção nos processos históricos que lhes constituem e que se manifesta de diversas maneiras. O poeta Gonzaguinha, por exemplo, expressa esse poder do povo brasileiro na canção "Pequena memória para um tempo sem memória"33:

E tantos são os homens por debaixo das manchetes

São braços esquecidos que fizeram os heróis

São forças, são suores que levantam as vedetes

Do teatro de revistas, que é o país de todos nós

${ }^{3}$ Disponível em: https://www.letras.mus.br/gonzaguinha/1772122/. Acesso em: 10 ago. 2020. 
A conscientização do ser é um ato político-pedagógico que se materializa a partir das relações sociais, de humanidade e de humanização dos sujeitos de direito. Esse pensar encontra amparo na teoria freireana que preconiza a emancipação dos homens e das mulheres, dos trabalhadores e das trabalhadoras do campo e da cidade, pelo direito a uma educação referenciada nas suas experiências.

Paulo Freire enfatiza na sua obra as questões de humanidade, de humanização e de desumanização dos sujeitos, na certeza de contribuir com o debate social e para a compreensão de que somos seres inconclusos e que precisamos ter consciência dessa condição. Sobre isso, ele afirma:

A desumanização, que não se verifica, apenas, nos que tem sua humanidade roubada, mas também, ainda que de forma diferente, nos que a roubam, é distorção da vocação do ser mais. [...]. A luta pela humanização, pelo trabalho livre, pela desalienação, pela afirmação dos homens como pessoas, como "seres para si", não teria significação. Esta somente é possível porque a desumanização, mesmo que um fato concreto na história, não é, porém, destino dado, mas resultado de uma "ordem" injusta que gera a violência dos opressores e esta, o ser menos. (FREIRE, 1987, p. 16).

A desumanização é parte de um processo histórico de opressão que impõe uma educação marginalizadora, excludente e opressora. Assim, há de buscar-se nas lutas sociais os meios para a recuperação da humanização; nesse sentido, a tarefa humanista e histórica dos oprimidos será libertarem-se a si mesmos e aos opressores que os exploram e os violentam. A força da libertação dos oprimidos nasce, portanto, da sua generosidade para a libertação de ambos, a qual, por sua vez, reside na fraternidade irradiada nos homens e nas mulheres historicamente subjugados e que lutam para restaurar a humanização da humanidade.

É preciso ter em mente, no entanto, que a aprendizagem não está apenas no final do percurso; ao contrário, ela está no percurso da humanização. Paulo Freire refere-se ao seu tempo de exílio como um de intensa aprendizagem sem, para tanto, ter precisado abdicar do direito de demonstrar a sua estranheza com relação ao momento vivido e, ao mesmo tempo, de perceber as diferenças, as peculiaridades e as belezas entre as culturas daqui e de lá.

Como educador democrata que aprendeu pelo mundo e com o mundo, Freire sempre defendeu a participação popular na transformação das sociedades, sobretudo daqueles e daquelas a quem lhes foi negado o direito de aprender e de ensinar. Isso corrobora a ideia de que, para ele, o saber não é propriedade deste ou daquele grupo social. De fato, a descoberta de um "gênio da ciência" adquire valor e reconhecimento somente se os novos conhecimentos por ele construídos forem acessados por seus pares e pela sociedade para serem testados, criticados e, eventualmente, validados. Esses elementos que evidenciam a relevância histórica do diálogo e da socialização de saberes para a construção da ciência também atravessam toda a obra de Paulo Freire.

Apesar de toda a sua generosidade, Freire continua sendo atacado por grupos que têm no ódio e na violência o seu método de "diálogo". A exemplo de outrora, como já acentuava Japiassu (1975) nos anos de 1980, esses grupos se abrigam no mito da ideologia da neutralidade científica, e isso tem reverberado, principalmente, no Ministério de Educação (MEC), cuja tônica no Governo atual está na troca constante de seus ministros. O primeiro, ao assumir o Ministério, apressou-se a fazer críticas a Paulo Freire e a Antônio Gramsci. Ele prometeu, como se fosse possível em um passe de mágica ideológica, "refundar" o Ministério para, nos seus devaneios, "valorizar a educação" e considerou que estaríamos em meio a um processo de domínio da ideologia marxista nas escolas que teria sido instalada a partir da teoria freireana. $\mathrm{O}$ ministro que veio em seguida propalou essas mesmas bases e fingiu ignorar a importância do legado de Paulo Freire para a 
educação no Brasil e no mundo, o que justifica o fato de ser um dos autores mais lidos e citados no Planeta.

A visão deliberadamente reducionista desses agentes públicos chama atenção pela denotada incapacidade de fazer uma análise da educação brasileira que não seja movida pelo ódio e pela falta de empatia com o que é diverso e diferente. A sanha de destruir o legado de Paulo Freire serve também de pretexto para justificar os cortes nos investimentos nas escolas e nas Universidades públicas, as quais, na visão distorcida desses agentes, devem ser destituídas de sua finalidade primeira que é a de educar em sentido pleno e omnilateral.

Os movimentos sociais de lutas populares da cidade e do campo estão vigilantes para não perderem os direitos conquistados pelo povo brasileiro, dentre os quais se incluem o Movimento da Educação do Campo, que tem seus princípios ancorados na teoria freireana. A forte relação entre esse Movimento e o legado de Paulo Freire está no centro das nossas reflexões e das pesquisas realizadas no GEPERUAZ. Para abordar esse aspecto, na próxima seção, partimos do diálogo que se estabelece entre os fundamentos da Educação Popular e da Educação do Campo para, após, apresentarmos algumas iniciativas que demonstram a força do legado freireano para a educação dos povos camponeses, das águas e das florestas.

\title{
Paulo Freire na Educação e na Escola do Campo
}

A Educação do Campo tem na Educação Popular, pensada e vivida por Paulo Freire, uma de suas principais bases filosóficas, sociológicas e políticas (CALDART, 2012). O Movimento da Educação Popular é sinônimo da mobilização das classes menos favorecidas que prosperaram no Brasil desde o meio do século passado, e ainda prosperam atualmente, apesar dos enfrentamentos e das tensões vivenciados no período obscuro da ditadura militar e que teimam em ressuscitar agora no governo de Bolsonaro.

O fortalecimento dos movimentos sociais populares, os esforços em torno do fortalecimento sindical no campo e na cidade, o crescimento dos centros populares de cultura e de campanhas como "De pé no chão também se aprender a ler", implantada por Paulo Freire na cidade de Natal, no Rio Grande do Norte, em 1961, estão na gênese do Movimento da Educação do Campo. Em seu livro Conscientização: movimento e prática para a libertação: uma introdução ao pensamento de Paulo Freire, encontramos registros históricos e os números que resultaram da referida campanha:

\begin{abstract}
Os resultados obtidos - 300 trabalhadores alfabetizados em 45 dias - impressionaram profundamente a opinião pública. Decidiu-se aplicar o método em todo o território nacional, mas desta vez com o apoio do Governo Federal. E foi assim que, entre junho de 1963 e março de 1964, foram realizados cursos de formação de coordenadores na maior parte das Capitais dos Estados brasileiros (no Estado da Guanabara se inscreveram mais de 6.000 pessoas; igualmente criaram-se cursos nos Estados do Rio Grande do Norte, São Paulo, Bahia, Sergipe e Rio Grande do Sul, que agrupavam vários milhares de pessoas). O plano de ação de 1964 previa a instalação de 20.000 círculos de cultura, capazes de formar, no mesmo ano, por volta de 2 milhões de alunos. (Cada círculo educava, em dois meses, 30 alunos). Assim começava, a nível nacional, uma campanha de alfabetização que haveria de alcançar primeiro as zonas urbanas, para estender-se imediatamente aos setores rurais. (FREIRE, 1979, p. 11).
\end{abstract}

O impressionante resultado dessa campanha e a ascensão popular que dela resultou despertaram o interesse de grupos reacionários que, como hoje, deflagaram uma campanha de ódio contra Paulo Freire, forçando-o ao exílio naquele momento. No entanto, a semente da Educação Popular germinou, cresceu e deu muitos frutos mesmo na adversidade. Um desses frutos é o Movimento da Educação do Campo que iniciou no final dos anos de 1990 do século XX e ganhou 
força e vigor nos anos 2000, nos governos de Luiz Inácio Lula da Silva e Dilma Rousseff. Esse movimento nasceu, portanto, na contradição do modelo de sociedade hegemônica no Brasil e afirmou as contribuições dos povos tradicionais e camponeses para a existência da sociedade brasileira e sua disposição de luta por uma educação de qualidade socialmente referenciada.

Em Pedagogia do oprimido, Freire (1987) acentua a relevância da contradição para a libertação dos povos historicamente oprimidos. Para ele, a tomada de consciência de si mesmos, como pessoas e membros da classe oprimida, amplia o olhar sobre o opressor e a opressão e dá lugar à libertação individual e comunitária. A conscientização da condição de oprimido faz ver que, para além da propriedade das terras em que vivem e trabalham, o opressor se julga proprietário do trabalhador, da trabalhadora e das classes populares que devem ser silenciadas, obedientes e mantidas sob controle. A vontade do opressor coaduna com o modelo de educação rural que visa perpetuar as situações de subalternização e de opressão impostas pelo agronegócio, entendido, por Alentejano (2020), como a associação do latifúndio com o grande capital agroindustrial nacional e transnacional, com o apoio - político e econômico - do Estado e com a sustentação ideológica da mídia.

$\mathrm{Na}$ contramão desse modelo, a Educação do Campo assenta as suas bases na teoria freireana e assume a noção da contradição como meio de transformar os oprimidos em libertados. Homens e mulheres livres que lutam pelo direito à terra, pela reforma agrária, pela soberania alimentar, pela educação e pelo reconhecimento de seus saberes e seus valores.

A obra Pedagogia da indignação: cartas pedagógicas e outros escritos (FREIRE, 2000) faz referência ao Movimento dos Trabalhadores Rurais Sem Terra (MST), o qual exerce um importante protagonismo no Movimento Nacional da Educação do Campo, desde a sua origem. Entre as raízes históricas e os fundamentos do Movimento, Freire destaca os quilombos e as Ligas Camponesas, os quais foram esmagados por forças retrógradas do imobilismo reacionário, colonial e perverso.

O importante, porém, é reconhecer que os quilombos tanto quanto os camponeses das Ligas e os sem-terra de hoje todos em seu tempo, anteontem, ontem e agora sonharam e sonham o mesmo sonho, acreditaram e acreditam na imperiosa necessidade da luta na feitura da história como "façanha da liberdade". No fundo, jamais se entregariam à falsidade ideológica da frase: “a realidade é assim mesmo, não adianta lutar". Pelo contrário, apostaram na intervenção no mundo para retificá-lo e não apenas para mantêlo mais ou menos como está. (FREIRE, 2000, p. 28).

Freire aponta o sonho de liberdade, o inconformismo, a força e a coragem de intervir no mundo como características comuns às trabalhadoras negras e aos trabalhadores negros que constituíram os quilombos, as Ligas Camponesas e o MST. Homens e mulheres que não aceitam as imposições do poder e constroem processos democráticos poucas vezes vistos na história do Brasil e da América Latina. Assim, Freire saúda a marcha dos sem-terra e louva a boniteza da luta e as contribuições para a consolidação democrática. O Movimento Nacional da Educação do Campo admite esses princípios, e outros que deles derivam, como a problematização e a crítica à realidade, a constituição de coletivos, a intervenção social, a proposição de projetos contra hegemônicos de sociedade e de educação.

Em Pedagogia do oprimido, Freire (1987) também traz o debate sobre a reforma agrária, e assim resgata a noção de comunhão com o povo. Isso traduz o engajamento dos sujeitos do campo na luta pela Educação do Campo que, por meio da mobilização social, reivindicam o direito a uma educação pública, gratuita, laica e que valoriza a identidade, a história, a cultura, os modos de vida, de trabalho e de produção dos camponeses e das camponesas. Uma educação com essas bases propicia o acesso ao conhecimento crítico socialmente construído a partir de um processo 
libertador que visa a emancipação social. Essas são as evidências próprias do legado freireano e da Educação Popular em marcha na Educação do Campo.

Ao tomarmos por base essa premissa, um questionamento parece-nos eminente: Como essa concepção de educação pode se materializar em um sistema de educação com bases universalistas? A resposta perpassa diversos aspectos dos processos educativos, desde a educação escolar até a formação inicial e continuada de professores e de professoras do campo. Nesse contexto, uma nova escola é requerida pelos coletivos diversos que vivem no campo: a Escola do Campo.

\section{A Escola do Campo}

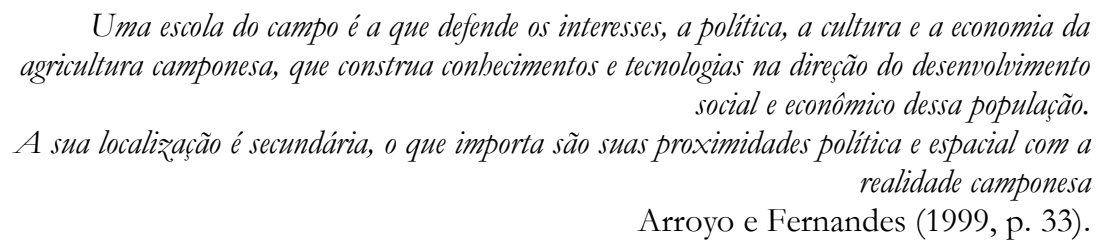

A Escola do Campo caracteriza-se, prioritariamente, pelo protagonismo dos seus sujeitos educativos com suas histórias, seus saberes e suas culturas, como também pelas características do território no qual está inserida. Ela é uma construção coletiva que faz parte das lutas dos povos do campo por um projeto de sociedade e de educação que vem sendo construído em meio aos conflitos e às disputas com o latifúndio/Agro/Hidro/Mineralnegócio, assim como às disputas com o ensino universalista representado, sobretudo, pelos grandes conglomerados educacionais. Essa escola traz na sua constituição os princípios da Educação do Campo e nasce com a força necessária para romper com a concepção que sustenta a educação rural que, como dissemos, nega o camponês e a camponesa como sujeitos de direitos.

Com base nas reflexões de Molina e Sá (2012), afirmamos que a escola do campo

[...] se enraíza no processo histórico da luta da classe trabalhadora pela superação do sistema do capital, assentando-se no entendimento de que a luta pela democratização da terra, requisito para a construção de outro modelo de desenvolvimento exige a garantia do direito à educação e à escolarização dos sujeitos do campo para a sua formação humana omnilateral, no sentido marxiano, tendo em vista a formação de novas gerações de intelectuais orgânicos, no sentido Gramsciano, capazes de conduzir o protagonismo dos sujeitos que vivem do trabalho no campo em direção à consolidação de uma hegemonia da classe trabalhadora. (HAGE; LIMA; SOUZA, 2017, p. 3).

O conceito de escola do campo está intrinsicamente ligado à luta pela democratização da terra e pressupõe uma formação humana e omnilateral. Estas são virtudes apreendidas da Educação Popular que pressupõe e propõe uma formação referenciada nas realidades e baseada nas aspirações de liberdade, de emancipação humana, de igualdade e de felicidade. Esses conceitos oriundos da Educação Popular estão em marcha nos processos educativos que ocorrem nas escolas do campo. Caldart (2000) corrobora esse entendimento quando resgata as reflexões de Paulo Freire na Pedagogia do oprimido e destaca o papel da escola na transformação das realidades e, sobretudo, no compartilhamento e na socialização de conhecimentos.

No caso dos territórios do campo, a transformação de suas realidades passa necessariamente pela democratização da terra, pois a felicidade que é própria do camponês e da camponesa emana da terra, que é vetor das relações humanas, de produção e de trabalho e, principalmente, fonte de alimentação saudável com base nos princípios agroecológicos. 
A luta da escola e pela escola do campo coloca-nos na situação de resgate da formação humana que se perdeu ao longo da história e que tem a centralidade no diálogo entre todos os sujeitos do processo educativo que se concretiza dialeticamente. Como afirmam Arroyo e Fernandes (1999), propor uma Educação Básica do campo exige mais do que trabalhar com os saberes escolares que, ao longo do tempo, têm sido considerados utilitários, a exemplo daqueles que estão nos livros didáticos ou são prescritos pela Base Nacional Curricular Comum - BNCC (BRASIL, 2017) em vigor no Brasil. Mesmo que os conhecimentos científicos tenham relevância para os processos educativos nas escolas do campo, ressaltamos que eles não são os únicos meios necessários para a leitura do mundo, a qual, na visão de Freire, precede a leitura das palavras.

A escola tem a função de socializar, de trabalhar e de articular as noções de tempo e de espaço, de trabalhar os valores humanísticos e culturais que constituem as pessoas em seus coletivos sociais. Paulo Freire dizia que aprender a ler o mundo é tão importante quanto aprender a ler a cartilha. Para ele, "[...] aprender a ler, a escrever, alfabetizar-se é antes de qualquer coisa aprender a ler o mundo, compreender o contexto, não numa manipulação mecânica de palavras, mas numa relação dinâmica que vincula linguagem e realidade" (FREIRE, 1989, p. 7). A escola do campo tem, portanto, esses fundamentos que são originários do legado freireano e da Educação Popular.

Certamente, não há Escola do Campo em um campo sem perspectivas, com povos sem horizonte e sem vida, como também não há um projeto popular de desenvolvimento do campo sem que a escola tenha um projeto de educação. Em consonância com Caldart (2003), entendemos que a escola se constitui como um espaço importante para a conscientização das pessoas de suas próprias necessidades, inclusive de organizar-se em coletivos para lutar por um projeto de campo contra hegemônico. A concretização dos princípios da Educação do Campo na escola requer, portanto, a sua (re)organização e o seu redimensionamento das práticas docentes adotadas pelas educadoras e educadores para ensinar nessa perspectiva. A educação vivenciada na escola do campo precisa ser referenciada por quem melhor conhece as realidades das comunidades nas quais estão inseridas: os seus sujeitos de direito. Para isso, adotam a pedagogia freireana cujos princípios educativos estão ancorados no trabalho, na pesquisa e na valorização da identidade e da cultura de seus sujeitos.

No entanto, uma questão que se impõe: Que instrumentos as escolas do campo dispõem para cumprir o seu papel? Uma das respostas passa, seguramente, pelo diálogo tão valorizado por Paulo Freire como fundante do processo educativo. O diálogo como meio de reunir os iguais para construir estratégias de afirmação da diversidade e, ao mesmo tempo, de reunir os diferentes para encontrar a unidade e, assim, superar os desafios comuns a grupos sociais diversos. Todavia, a pesquisa de Galli (2015) mostra que o diálogo em Freire vai mais além. Ao analisar o conceito de diálogo na Pedagogia do oprimido (FREIRE, 1987), principal fundamento da teoria freireana, e na Pedagogia da esperança (FREIRE, 2008), que revisita a primeira, o pesquisador conclui: "Identificamos que o diálogo muda de posição na teoria de Freire, ou seja, passa de um meio para atingir a transformação para ser a própria transformação, tanto no âmbito do sujeito como em sua relação com o mundo em que vive" (GALLI, 2015, p. 144).

Visualiza-se, assim, a força do diálogo como fundamento da Educação Popular em marcha na Educação e na Escola do Campo. Na declaração "Por uma Educação do Campo", encontramos a seguinte premissa que corrobora essa afirmação: "Nossa perspectiva deve ser a do diálogo: somos diferentes e nos encontramos como iguais para lutar juntos pelos nossos direitos de ser humano, de cidadão, e para transformar o mundo" (CALDART, 2003, p. 42).

O diálogo propicia a utilização de outro instrumento essencial para a educação nas escolas do campo: a Pedagogia da alternância, que diz respeito às formas de organização do trabalho 
pedagógico em tempos e em espaços diferenciados e inter-relacionados. Como acentua Gimonet, (2007), ela tem suas raízes na França, nas décadas iniciais do século XX, quando famílias agricultoras, preocupadas com a escolarização e o futuro dos filhos, empreenderam esforços para criar uma escola cujo funcionamento possibilitasse a permanência deles junto à família e que também criasse condições para que o projeto pedagógico atendesse às demandas das formas de vida vinculadas aos seus modos de existência.

No Brasil, a primeira experiência iniciou no estado do Espírito Santo, em 1969, na cidade de Anchieta. Ela teve o apoio da igreja católica e, aos poucos, foi se constituindo como uma rede de ensino, de modo a receber denominações diferenciadas em diversas regiões brasileiras, como Escolas Famílias Agrícolas (EFA), Casas Familiares Rurais (CFR) e Escolas Comunitárias Rurais (ECOR); e, atualmente, organizam-se nacionalmente por meio do Movimento Centros Educativos Familiares de Formação por Alternância (CEFFA).

No âmbito do Movimento Nacional de Educação do Campo, desde a sua criação, a Alternância constitui-se como uma estratégia teórico-metodológica de formação dos sujeitos do campo ancorada na relação Trabalho-Educação-Território, a qual tem como intencionalidade constituir-se como um processo educativo potencializador das dimensões que são estruturantes das formas de produzir e de reproduzir a existência no contexto do campesinato. Ela tem sido utilizada como uma referência para organizar o trabalho pedagógico na perspectiva de relacionar a escola com os sujeitos, as suas famílias e as suas organizações sociais, em seus diferentes espaços e temporalidades, o que deu origem aos termos "Tempo Escola"/"Universidade" e "Tempo Comunidade".

A Pedagogia da Alternância coaduna-se com a história de Paulo Freire, na medida em que foi enriquecida ao longo dos anos pelas experiências vivenciadas em diferentes realidades e contextos socioculturais. Ela se tornou uma das estratégias mais apropriadas para a educação/escolarização dos povos do campo, das águas e das florestas e para a formação das professoras e dos professores que atuam nesses territórios. Sua relevância consiste em reconhecer que diferentes tempos, espaços e saberes são educativos e, portanto, contribuem com a formação dos sujeitos do campo.

Quando vivenciada em sua inteireza, a Pedagogia da Alternância provoca mudanças na dinâmica da organização do calendário escolar, do trabalho das educadoras e dos educadores, do planejamento curricular e, por consequência, dos processos de produção do conhecimento. $\mathrm{O}$ diálogo passa a ser um elemento fundante na constituição desses processos, ao incluir o respeito às especificidades das comunidades, suas culturas, seus modos de vida e as necessidades do trabalho e da produção, a exemplo dos períodos do plantio, da colheita e da pesca, bem como os rituais culturais e religiosos.

Importante esclarecermos que as referências aqui apresentadas não se restringem a uma simples narrativa; ao contrário, elas têm a força da legislação que expressa os anseios das camponesas e dos camponeses, dos coletivos e dos movimentos sociais que lhes representam. Elas têm a força das ações que nasceram e têm se frutificado nos últimos 20 anos da Educação do Campo e que estão bem representadas no Fórum Nacional de Educação do Campo (Fonec), que há dez anos se constitui como um espaço coletivo de reflexão, proposição e ação (SANTOS et al., 2020).

Das ações de formação inicial e continuada de educadores e de educadoras do campo que são vivenciadas na perspectiva da Pedagogia da Alternância, destacam-se o Programa Nacional de Educação na Reforma Agrária (Pronera), a Ação Escola da Terra e as Licenciaturas em Educação do Campo, os quais apresentamos, em grandes linhas, a seguir. 


\section{O Programa Nacional de Educação na Reforma Agrária - Pronera}

O Pronera teve sua criação em meio ao I Encontro Nacional de Educadores da Reforma Agrária (Enera), realizado em 1997, e a I Conferência Nacional por uma Educação Básica do Campo (CNEBC), realizada em 1998.

Fundado com base nos princípios da Educação do Campo, o Pronera, ao longo de seus 20 anos, potencializou o desenvolvimento de projetos de educação e de escolarização, de modo a considerar as especificidades socioambientais e a diversidade cultural do campo em todos os estados brasileiros. Conforme consta no Relatório da II Pesquisa Nacional sobre a Educação na Reforma Agrária - II PNERA (BRASIL, 2015), o Pronera vem desencadeando a vivência de inovações pedagógicas e curriculares que são organizadas de acordo com as demandas dos sujeitos do campo envolvidos nos cursos. Desse modo, por meio do Pronera, a população beneficiária da política de reforma agrária, moradora de assentamentos da reforma agrária, tem acesso a uma diversidade de cursos pautados por princípios da Educação Popular e Educação do Campo, com destaque para a modalidade da Educação de Jovens e Adultos (EJA). São oferecidos, portanto, cursos técnicoprofissionais de nível médio: técnico em administração de cooperativas, enfermagem, técnico em saúde comunitária, técnico em comunicação; e em nível superior: Licenciatura em Pedagogia, História, Geografia, Sociologia, Ciências Naturais, Ciências Agrárias, Agronomia, Direito e Medicina Veterinária.

Em defesa do Pronera e do direito à Educação do Campo, o Fonec define o Programa da seguinte maneira:

O PRONERA é uma política pública forjada pelo protagonismo dos sujeitos coletivos do campo. Até sua criação, não havia registro, na história deste país, dos camponeses protagonizando uma política pública de educação cuja característica fundamental é a articulação entre três sujeitos de territórios diferenciados, mas que materializam uma nova ação do Estado: os movimentos sociais, sindicais de trabalhadores e trabalhadoras do campo, o corpo dos servidores do INCRA e as Universidades. (CALDAS, 2020, n.p.).

Mesmo sendo uma política pública, desde o Governo de Michel Temer e, principalmente, no Governo de Bolsonaro, um conjunto de medidas tem sido tomadas para inviabilizar o Programa que, pela sua inspiração no legado de Paulo Freire, tem os fundamentos democráticos como princípio e, desse modo, é vivenciado com a participação ativa dos sujeitos desde a sua formulação. As medidas legais tomadas por esses últimos governos, em que pese a resistência e as pressões do Movimento Nacional de Educação do Campo, têm promovido cortes significativos no orçamento destinado ao Programa e incidido na estrutura regimental no que concerne aos cargos e às competências do Instituto Nacional de Colonização e Reforma Agrária (Incra). Exemplos disso são a extinção da Coordenação Geral de Educação do Campo e Cidadania, que era responsável pela gestão do Programa, bem como a sujeição da política agrária do Incra ao Ministério da Agricultura, Pecuária e Abastecimento (MAPA).

\section{A Ação Escola da Terra}

A Ação Escola da Terra foi instituída pela Portaria No 579, de 2 de julho de 2013 (BRASIL, 2013a), no âmbito do Programa Nacional de Educação do Campo - Pronacampo (BRASIL, 2013b), com a finalidade de formar professoras e professores de escolas do campo e quilombolas que atuam, prioritariamente, em escolas multisseriadas. Essa ação de formação continuada é singular porque parte de uma ementa que é nacional, para em cada estado da federação brasileira se particularizar no atendimento das especificidades de cada comunidade do campo, das águas e das florestas (HAGE et al., 2018). Embora diversos na construção dos projetos políticos 
pedagógicos e nas suas vivências, as ações formativas unificam-se em torno do diálogo entre os saberes acadêmicos, científicos, escolares e populares. Esses saberes com os povos camponeses e as suas realidades tomam por base as referências do legado freireano.

Dessa maneira, resgatam-se as diversas culturas, as histórias de lutas, os modos de vida, de produção e de trabalho, elementos de diálogo com os saberes escolares das diversas áreas de conhecimento estudadas na Educação Básica, como a Língua Portuguesa, a Matemática, as Ciências Humanas e da Natureza. Desse modo, a Escola da Terra segue a perspectiva dialógica de inspiração freireana e promove um amplo diálogo, inclusive com os princípios e os saberes da Agroecologia na formação das professoras e dos professores do campo pela estreita relação que têm com a agricultura camponesa cultivada sem agrotóxicos, em nome da saúde e do bem-viver.

Atualmente, por meio dessa ação formativa, contabiliza-se mais de 20.000 educadoras e educadores do campo que concluíram seus cursos de aperfeiçoamento ou de especialização lato sensu em Educação do Campo, oferecidos pelas Universidades públicas federais brasileiras em parcerias com as Secretarias Estaduais e Municipais de Educação, os movimentos sociais e as outras organizações sociais. Como expressa o conjunto de capítulos que compõem o livro Programa Escola da Terra: cartografia da diversidade e complexidade de sua execusão no Brasil (HAGE et al., 2018), a Pedagogia da Alternância, implementada nesse Programa, possibilita a dialogia que se estabelece entre os binômios campo-cidade, rural-urbano, universal-local e afirmativo-democrático.

\section{A Licenciatura em Educação do Campo}

A Licenciatura em Educação do Campo é um curso de Graduação criado em 2007 pelo MEC, com o apoio da Secretaria de Educação Continuada, Alfabetização e Diversidade (Secad) ${ }^{4}$, com o objetivo de formar professores e professoras para ensinar nos anos finais do Ensino Fundamental e do Ensino Médio nas escolas do campo, como também para atuar na gestão de processos educativos escolares e sociais. Os cursos são ofertados pelas Universidades públicas brasileiras e pelos Institutos Federais de Educação e contemplam as áreas de Ciências Agrárias, Artes e Linguagens, Ciências Humanas, Ciências da Natureza e Matemática ${ }^{5}$.

Essa licenciatura é fruto de uma luta histórica dos povos do campo pela garantia do direito educacional de atendimento à população do campo. Nela, são observadas as especificidades quanto à dinâmica de vida, aos saberes advindos da relação com o trabalho e, sobretudo, ao vínculo com a terra. Trata-se, portanto, de uma formação diferenciada, vivenciada a partir de propostas curriculares que integram as áreas do conhecimento e, por meio de práticas didático-pedagógicas diferenciadas, que dialogam com as realidades das licenciandas e licenciandos. Para isso, referenciase na alternância que propicia a relação entre os saberes das diferentes áreas com outros que derivam das dimensões políticas, sociais e culturais, entre outras, de modo a contribuir tanto com o processo formativo quanto com o trabalho que será desenvolvido nas escolas do campo.

As práticas formativas da Licenciatura em Educação do Campo têm como fundamento o perfil do profissional que se intenciona formar, em conjunto aos movimentos sociais e sindicais participantes desse processo histórico, com uma compreensão ampliada de seu papel, que entenda a educação como prática social necessária para promover a inter-relação dos diversos saberes com a escolarização e como promotora de vida nos territórios camponeses. Espera-se também que os

\footnotetext{
${ }^{4}$ Posteriormente, nominada Secretaria de Educação Continuada, Alfabetização, Diversidade e Inclusão (Secadi).

${ }^{5}$ Os cursos implementados a partir dois primeiros editais (BRASIL, 2008, 2009) trabalham a Matemática integrada às Ciências da Natureza.
} 
processos educativos contribuam para a construção de uma estreita relação entre a universidade, a escola e a comunidade.

Assim, as Licenciaturas em Educação do Campo também se aproximam do legado freireano ao exercitar o diálogo como referência de formação de professoras e professores. Para que isso ocorra, os sujeitos educativos que compõem os cursos se encontram quotidianamente desafiados a vivenciar processos formativos a partir de metodologias que possibilitem a articulação entre escola e comunidade e permitam a necessária dialética entre a educação e a experiência. Essa é a maneira de garantir um equilíbrio entre rigor intelectual e a valorização dos saberes produzidos em suas vivências socioculturais.

\section{Nossas considerações finais}

À guisa de conclusão da nossa reflexão, cabe-nos fazer um questionamento cuja resposta, na verdade, já é por nós conhecida: Quem tem medo de Paulo Freire e de suas contribuições para a educação? Certamente, o Brasil do presidente Jair Bolsonaro ao tentar impor uma narrativa que oprime, cada vez mais, o povo brasileiro e reforça o abismo que há entre o povo e os seus direitos. Nessa lógica perversa, para fazer valer tal narrativa, na qual o diálogo é impossível, as vozes dissonantes precisam ser silenciadas. Para tanto, utilizam artifícios que visam submeter a população brasileira ao dissabor de todo o dia ser surpreendida por uma avalanche de decisões intempestivas que afetam as bases do país, inclusive o sistema educacional.

As atitudes dos agentes que atualmente estão alojados em postos-chave da educação e em outras instâncias governamentais, como a cultura, a saúde e o meio ambiente, refletem o pensamento bolsonarista e buscam acirrar a disputa entre os projetos societários que estão em campos antagônicos. De um lado, um projeto que insiste em ignorar o protagonismo popular; e, de outro, um projeto de sociedade centrado nas aspirações e nas necessidades da mulher e do homem como sujeitos de direito, de cultura e de saberes. Nesse estado de tensão social, o legado de Paulo Freire resplandece e aponta-nos o caminho a trilhar para a libertação e para a humanização dos oprimidos e, por consequência, de seus opressores. É com esse pensar que o Movimento Nacional de Educação do Campo se fortalece.

De fato, a complexa dinâmica do Movimento Nacional de Educação do Campo, por conseguinte da Reforma Agrária Popular por ele reivindicada, é uma construção humana e social. Como acentua Caldart (2020), o movimento se configura em uma experiência de formação das pessoas que dele participam. A escola do campo e os coletivos da Educação do Campo fazem parte dessa experiencia e vivenciam-na em sua plenitude.

As reflexões que trouxemos neste artigo contribuem também para reverberar os termos da Carta Manifesto do Fonec, produzida no seminário realizado em 2018, na Universidade de Brasília (UnB), em comemoração aos 20 anos da Educação do Campo e do Pronera. A carta explicita a abrangência e a significância do protagonismo do Movimento Nacional de Educação do Campo na sociedade brasileira, como se nota nos seguintes trechos:

16. [...]. Não é mais possível aos livros de História de Educação no Brasil não acrescentar mais um capítulo à sua periodização: a construção da Educação do Campo!

17. O protagonismo dos movimentos sociais populares e sindicais do campo, aliados aos realizados pela educação básica e superior de todo o país, juntos na luta pelo direito à educação dos camponeses, foi capaz de construir um imenso patrimônio de práticas educativas, que não pode mais ser apagado, porque fincou raízes dentro de nós: construímos juntos uma nova forma de educar. (FONEC, 2018, p. 3). 
As vivências dos povos do campo são processadas em cada consciência como sentimento, como pensamento, como linguagem e como sujeitos da práxis. O legado de Paulo Freire traz esses ensinamentos que contribuem para interpretar, compreender e comunicar essas vivências ao longo dos mais de 20 anos de mobilização e de luta Por uma Educação do Campo.

\section{Referências}

ALENTEJANO, P. R. R. Reforma agrária, caos urbano, agronegócio e pandemia. Revista Tamoios, São Gonçalo, v. 16, n. 1, p. 32-38, maio 2020. DOI: https://doi.org/10.12957/tamoios.2020.50242

ARROYO, M. G. Paulo Freire: um outro paradigma pedagógico? Educação em Revista, Belo Horizonte, v. 35, p. 1-20, 2019. DOI: https://doi.org/10.1590/0102-4698214631.

ARROYO, M. G.; FERNANDES, B. M. A Educação Básica e o movimento social do campo. Brasília: Secretariado Geral, 1999. (Coleção Por uma Educação Básica do Campo, n. 2).

BRASIL. Ministério da Educação. Secretaria de Educação Continuada, Alfabetização e Diversidade. Edital de Convocação no 02, de 23 de abril de 2008. Chamada pública para seleção de projetos de instituições públicas de ensino superior para o Procampo. Brasília, DF: Ministério da Educação, 2008.

BRASIL. Ministério da Educação. Secretaria de Educação Continuada, Alfabetização e Diversidade. Edital de Convocação no 09, de 29 de abril de 2009. Brasília, DF: Ministério da Educação, 2009.

BRASIL. Lei No 12.612, de 13 de abril de 2012. Declara o educador Paulo Freire Patrono da Educação Brasileira. Diário Oficial da União: seção 1, Brasília, DF, v. 149, n. 73, p. 1,16 abr. 2012.

BRASIL. Portaria No 579, de 2 de julho de 2013. Institui a Escola da Terra. Diário Oficial da União: seção 1, Brasília, DF, v. 150, n. 126, p. 11-12, 2 jul. 2013 a.

BRASIL. Programa Nacional de Educação do Campo - PRONACAMPO. Brasília, DF: Ministério da Educação, 2013b. Disponível em: http:/ / portal.mec.gov.br/index.php?option=com_docman\&view $=$ download\&alias $=13214$ documento-orientador-do-pronacampo-pdf\&Itemid=30192. Acesso em: 30 de jul. 2020.

BRASIL. Instituto de Pesquisa Econômica Aplicada. II PNERA: Relatório da II pesquisa nacional sobre a educação na reforma agrária. Brasília: IPEA, 2015. Disponível em: https://www.ipea.gov.br/portal/images/stories/PDFs/relatoriopesquisa/150618_relatorio_ii_p esquisa\%20nacional.pdf. Acesso em: 8 ago. 2020.

BRASIL. Ministério da Educação. Base Nacional Comum Curricular. Brasília: MEC, 2017. Disponível em: http://basenacionalcomum.mec.gov.br/images/BNCC_EI_EF_110518_versaofinal_site.pdf. Acesso em: 8 mar. 2021.

BRASIL. Duas sugestões legislativas são rejeitadas na CDH. Agência Senado, Brasília, 5 set. 2019. Disponível em: https://www12.senado.leg.br/noticias/materias/2019/09/05/duas-sugestoeslegislativas-sao-. Acesso em: 8 mar. 2020. 
CALDART, R. S. A escola do campo em movimento. Currículo sem Fronteiras, [s. l.], v. 3, n. 1, p. 60-81, jan./jun. 2003.

CALDART, R. S. Educação do Campo. In: CALDART, R. S. et al. (org.). Dicionário da educação do campo. Rio de Janeiro: Escola Politécnica de Saúde Joaquim Venâncio, São Paulo: Expressão Popular, 2012. p. 257-272

CALDART, R. S. Reforma Agrária Popular e Educação. IV Jornada Universitária em Defesa da Reforma Agrária - JURA. Vitória da Conquista, 2020. Disponível em: https://www.youtube.com/watch?v=61R5TDA6rgk\&t=1250s. Acesso em: 15 mar. 2021.

CALDAS, A. C. Com fim do Pronera, Bolsonaro ataca educação dos povos do campo - Em defesa do PRONERA e do direito à Educação do Campo. Brasil de Fato, Curitiba, 28 fev. 2020. Disponível em: https://www.brasildefato.com.br/2020/02/28/com-fim-do-pronera-bolsonaroataca-educacao-dos-povos-do-campo. Acesso em: 6 ago. 2020.

CEAAL. Conselho de Educação Popular da América Latina e do Caribe. Manifesto de lançamento da Campanha Latino-Americana e Caribenha em defesa do Legado de Paulo Freire. 2019. Disponível em: http://ceaal.org/v3/manifiesto-campana-defensa-legado-freire/. Acesso em: 8 mar. 2020.

FONEC. Fórum Nacional de Educação do Campo. Carta-Manifesto - 20 anos da Educação do Campo e do Pronera. Educação é Direito. Não é Mercadoria. Fonec, 2018. Disponível em: https://unifesspa.edu.br/images/manifesto_FORUM_NACIONAL_DE_EDUCA\% $\% 3 \% 87 \% \mathrm{C}$ 3\%83O_DO_CAMPO.pdf. Acesso em: 15 mar. 2021.

FREIRE, P. Educação como prática da liberdade. Rio de Janeiro: Paz e Terra, 1967.

FREIRE, P. Conscientização: movimento e prática para a libertação: uma introdução ao pensamento de Paulo Freire. São Paulo: Cortez \& Moraes, 1979.

FREIRE, P. Pedagogia do oprimido. 17. ed. Rio de Janeiro: Paz e Terra, 1987.

FREIRE, P. A importância do ato de ler: em três artigos que se completam. São Paulo: Cortez Editora \& Autores Associados, 1989. (Coleção Polêmicas do Nosso Tempo, v. 4).

FREIRE, P. Pedagogia da indignação: cartas pedagógicas e outros escritos. São Paulo: Editora Unesp, 2000.

FREIRE, P. Pedagogia da esperança: reencontro com a Pedagogia do oprimido. 15. ed. Rio de Janeiro: Paz e Terra, 2008.

FRIGOTTO, G. A produtividade da escola improdutiva: um (re)exame das relações entre educação e estrutura econômico-social capitalista. São Paulo: Cortez Editora, 1984.

GALLI, E. F. O diálogo em Paulo Freire: uma análise a partir da pedagogia do oprimido e da pedagogia da esperança. 2015. Dissertação (Mestrado em Educação) - Universidade Federal de São Carlos, São Carlos, 2015.

GIMONET, J. Praticar e compreender a pedagogia da alternância dos CEFFAs. Tradução Thierry de Burghgrave. Petrópolis: Vozes, 2007. (Coleção Aidefa - Alternativas Internacionais em Desenvolvimento, Educação, Família e Alternância). 
HAGE, S. M.; LIMA, I. M. S.; SOUZA, D. D. L. A escola do campo na perspectiva dos movimentos sociais: referências para o debate. In: REUNIÃO DA ANPED, 38., 2017, São Luís. Anais [...]. São Luís: ANPEd, 2017. p. 1-16.

HAGE, S. A. M. et al. (org.). Programa escola da terra: cartografia da diversidade e complexidade de sua execução no Brasil. Curitiba: CRV, 2018.

JAPIASSU, H. O mito da neutralidade científica. Rio de Janeiro: Imago Editora, 1975.

MOLINA, M. C.; SÁ, L. M. Escola do Campo. In: CALDART, R. S. et al. (org.). Dicionário da Educação do Campo. São Paulo: Expressão Popular, 2012. p. 326-333.

SANTOS, C. A. et al. (org.). Dossiê educação do campo: documentos 1998-2018. Brasília: Universidade de Brasília, 2020.

Recebido em 18/08/2020

Versão corrigida recebida em 04/03/2021

Aceito em 05/03/2021

Publicado online em 19/03/2021 